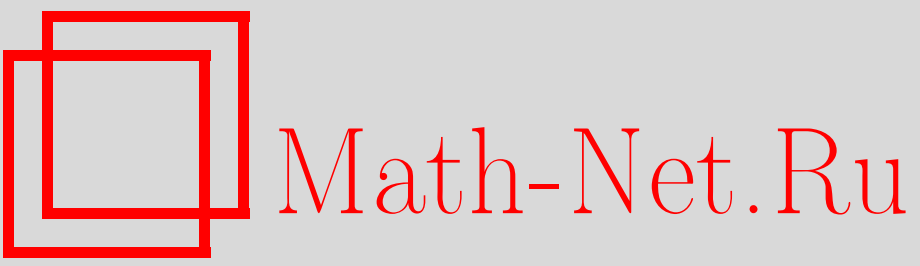

А. И. Бобенко, А. М. Ильин, С. Ю. Доброхотов, А. Р. Итс, Л. А. Калякин, В. Б. Матвеев, В. Ю. Новокшенов, А. Б. Шабат, Рамиль Фаритович Бикбаев (некоролог), УМH, 1996, том 51, выпуск 1, 133-136

DOI: https://doi.org/10.4213/rm1571

Использование Общероссийского математического портала Math-Net.Ru подразумевает, что вы прочитали и согласны с пользовательским соглашением http://www.mathnet.ru/rus/agreement

Параметры загрузки:

IP : 35.173 .219 .149

26 апреля 2023 г., 10:12:09 


\section{РАМИЛЬ ФАРИТОВИЧ БИКБАЕВ}

16 июля 1995 года в результате несчастного случая трагически оборвалась жизнь талантливого математика Рамиля Фаритовича Бикбаева, доктора физико-математических наук, ведущего научного сотрудника Института математики Уфимского научного центра РАН.

Р.Ф. Бикбаев родился в 1961 году в Уфе. После окончания уфимской средней школы № 105 он поступил в 1978 году в Ленинградский Технологический институт. После окончания первого курса он перевелся на физический факультет Ленинградского университета, который успешно закончил в 1984 году. Будучи студентом старших курсов, Р. Ф. Бикбаев специализировался по кафедре математической физики, где его учителями были М.Ш. Бирман, В.С. Буслаев, Б. С. Павлов, В.Б. Матвеев и А.Р. Итс. Особое влияние на формирование его научных интересов оказал А.Р. Итс, которьй стал руководителем его дипломной работы. Различные аспекты теории солитонов, стоявшей на приоритетном месте в математической физике 80-х годов, стали основным предметом исследований Р. Ф. Бикбаева, которые он продолжал до конца своей жизни.

Поступив после окончания университета в аспирантуру при кафедре математической физики физфака ЛГУ (руководители В.Б. Матвеев и А.Р. Итс), он сосредоточился на задачах теории конечнозонного интегрирования различных солитонных уравнений.

Совместно с А. И. Бобенко и А.Р. Итсом им впервые было проинтегрировано уравнение Ландау-Лифшица, что потребовало оригинального использования теории накрытий римановых поверхностей [1]-[3]. Помимо точных конечнозонных решений для этого уравнения им были построены асимптотические решения при больших временах, обобщаюшие известную схему Захарова-Манакова [5], [6]. В это же время он построил конечнозонные решения уравнений массивной модели Тирринга [4].

После успешной защиты кандидатской диссертации в 1986 году, Р. Ф. Бикбаев возвращается в У фу и поступает на работу в Отдел физики и математики (позже Институт математики) Уфимского научного центра. Здесь, будучи сотрудником Лаборатории дифференциальных уравнений, его внимание привлекают асимптотические методы теории дифференциальных уравнений, которые составляли основную тематику работ ее научного коллектива. Он начинает заниматься задачей об эволюции при больших временах начального условия типа ступеньки для уравнения Кортевега-де Фриза. В этой задаче нашли применение разнообразные методы из арсенала теории солитонов: прямое и обратное спектральные преобразования, задача Римана, метод усреднения Уизема в его конечнозонной формулировке. Совместно с В. Ю. Новокшеновым он доказал ключевые утверждения о монотонности групповых скоростей в уравнениях Уизема [7], описывающих модулированное конечнозонное решение Кд $\Phi$, “склеивающее” ступенчатые граничные условия при $t \rightarrow \infty$. Эти утверждения, в свою очередь, позволили доказать однозначную разрешимость 
системы Уизема для произвольных конечнозонных граничных условий [15], [16]. Выбирая далее деформированную по Уизему риманову поверхность и функцию Бейкера-Ахиезера на ней в качестве асимптотического анзаца, ему удалось "раздеть" задачу Римана при $t \rightarrow \infty$ и вывести формулы для главного члена потенциала. Существенную роль в этом сыграла разработанная совместно с Р. А. Шариповым модификация метода Манакова, приспособленная для анализа системы сингулярных интегральных уравнений на гиперэллиптических римановых поверхностях [10]. В дальнейшем эти результаты были перенесены Р. Ф. Бикбаевым на другие солитонные уравнения [17]-[23], [28], [31] и значительно обобщены в направлении замены вычислений инвариантными доказательствами. Они составили основное содержание его докторской диссертации, защищенной в С.-Петербургском отделении МИРАН в 1992 году.

Другим направлением, заинтересовавшим его еще в годы аспирантуры, стало применение метода Склянина для построения точно интегрируемых граничных условий для солитонных уравнений. Ключевым моментом в таких задачах является правильный выбор аналитических характеристик данных рассеяния и $\Psi$-функции для продолжения потенциала при всех $x \in \mathbb{R}$, сохраняющего граничные условия. В работах [24], [25] эта задача была решена в явном виде для нелинейного уравнения Шрёдингера (НШ) и уравнения синус-Гордон $(\mathrm{CГ})$ на полуоси с условием убывания на бесконечности. Для периодических решений $\mathrm{C} Г$ на отрезке в работе [30] совместно с А.Р. Итсом были найдены условия на матрицу периодов, которые обеспечивают периодичность соответствующего конечнозонного решения.

Будучи физиком по образованию, Р. $\Phi$. Бикбаев всегда питал ск лонность к приложениям полученных им математических результатов. Так, в связи с найденными им автомодельными решениями уравнений Уизема, он исследует задачу о гидродинамическом скачке на мелкой воде [23], [26]. Точные формулы для решений уравнения Ландау-Лифшшица нашли приложение в работе [9] для описания волн намагниченности вдоль легкой оси магнетика. Динамика доме́нных стенок в магнетике Гейзенберга описана им в работах [33], [36]. Два последних года своей жизни он посвятил изучению явления модуляционной неустойчивости, возникающей в нелинейных фокусирующих средах. Здесь ему удалось существенно продвинуться в понимании уиземовских деформаций с комплексными групповыми скоростями [40]-[42].

Широкий математический кругозор позволял Р. $\Phi$. Бикбаеву получать резултаты в достаточно отдаленных от его основных интересов областях математики. Так, в работе [39] он изучал возможность глобальной параметризации торов постоянной средней кривизны. Совместно с С.Б. Куксиным он внес существенный вклад в разработку бесконечномерного варианта КАМ-теории [29], [32], что привело его к доказательству гипотезы Кричевера о глобальной обратимости преобразования "точки ветвления - частотные векторы" для вещественных конечнозонных решений КдФ [38].

Трагическая гибель молодого ученого в расцвете творческих сил является тяжелым ударом для всех его коллег и особенно для небольшого коллектива математиков, работающих в Уфе. Будучи яркой разносторонней личностью Рамиль Фаритович оставил глубокий след в душах знавших его людей. Общение с ним неизменно было творческим и доставляло радость друзьям и коллегам.

Светлая память о Рамиле Фаритовиче Бикбаеве навсегда сохранится в наших сердцах.

А.И. Бобенко, С.Ю. Доброхотов, А.М. Ильин, А.Р. Итс, Л. А. Калякин, В. Б. Матвеев, В. Ю. Новокиенов, А. Б. Шабат

\section{СПИСОК ПЕЧАТНЫХ ТРУДОВ Р. Ф. БИКБАЕВА}

[1] О конечнозонном интегрировании уравнения Ландау-Лиффшица // ДАН СССР 1983. Т. 272. С. 1293-1296 (совм. с Бобенко А.И., Итс А.Р.)

[2] On finite-gap integration of the Landau-Lifshitz equation. XYZ case. // Preprint LOMI, E-8-83, 1983 (with Bobenko A.I.)

[3] Уравнение Ландау-Лифшица. Теория точных решений. Ч. I, Ч. II. Препринт Донецкого ФТИ N 84-6. Донецк, 1984 (совм. с Бобенко А. И., Итс А.Р.)

[4] Конечнозонные решения массивной модели Тирринга // ТМФ. 1985. Т. 63. С. 77-87 
[5] Асимптотика при $t \rightarrow \infty$ решения задачи Коши для уравнения Ландау-Лифшшица // ТМФ. 1988. Т. 76. С. $3-17$ (совм. с Итс А.Р.)

[6] Об асимптотике при $t \rightarrow \infty$ решения задачи Коши для уравнения Ландау-Лифшшица // ТMФ. 1988. T. 77. C. $163-170$

[7] Self-similar solutions of the Whitham equations and KdV equation with finite-gap boundary conditions // Proc. III Internat. Workshop on turbulent and nonlinear processes in physics. V. 1. Kiev: Naukova Dumka, 1988. P. 32-35 (with Novokshenov V. Yu.)

[8] Уравнение КдФ с конечнозонными граничными условиями // Препринт Башкирского научного центра. Уфа, 1988

[9] Magnetization waves in the Landau-Lifshitz model // Phys. Lett. A. 1988. V. 134. P. 105-107 (with Sharipov R. A.)

[10] Асимптотика при $t \rightarrow \infty$ решения задачи Коши для уравнения Кд $\Phi$ в классе потенциалов с конечнозонным поведением при $x \rightarrow \pm \infty / /$ ТМФ. 1989. Т. 78. С. 345-356 (совм. с Шариповым Р. А.)

[11] Алгебро-геометрические решения граничной задачи для нелинейного уравнения Шрёдингера // Матем. заметки. 1989. Т. 45. С. 3-9 (совм. с Итс А.Р.)

[12] Асимптотика при больших временах решения нелинейного уравнения Шрёдингера с граничными условиями типа ступеньки // ТМФ. 1989. Т. 81. С. 3-11

[13] О классе конечнозонных решений XXZ-модели уравнения Ландау-Лифшшиа // Матем. заметки. 1989. Т. 46. С. $112-114$

[14] О распределении намагниченности в легкоплоскостном ферромагнетике // ТМФ. 1989. Т. 80. C. $470-474$

[15] Уравнение Кд $\Phi$ с конечнозонными граничными условиями и однопараметрические решения уравнений Уизема / / Асимптотические методы в задачах математической физики. Уфа, 1989. С. 9-24 (совм. с Новокшеновым В. Ю.)

[16] // Сушествование и единственность решений уравнений Уизема. Уфа: Ibid, 1989. С. 81-96 (совм. с Новокшеновым В. Ю.)

[17] О дифракции в дефокусируюшей среде // Зап. науч. семинаров ЛОМИ. 1989. Т. 179. С. 23-32

[18] Гиперболические системы Уизема и интегрируемые уравнения / / Зап. науч. семинаров ЛОМИ. 1989. Т. 180. С. $23-36$

[19] Уравнение КдФ с конечнозонными граничными условиями и уиземовские деформации римановых поверхностей // Функц. анализ и его прилож. 1989. Т. 23. С. 1-10

[20] Structure of the shock wave in the theory of KdV equation // Phys. Lett. A. 1989. V. 56. P. 289-293

[21] Конечнозонные решения граничных задач для интегрируемых уравнений // Матем. заметки. 1990. Т. 48. С. 10-18

[22] Перестройка Уизема и временная асимптотика решения нелинейного уравнения Шрёдингера с конечнозонным поведением при $x \rightarrow \pm \infty / /$ Алгебра и Анализ. 1990. Т. 2. С. 131-141

[23] О задаче Коши для волн на мелкой воде // ТМФ. 1991. Т. 86. С. 474-480

[24] Initial-boundary problem for the nonlinear Schrödinger equation // Jour. Phys. A. 1991. V. 24. P. 2507-2517 (with Tarasov V.O.)

[25] Неоднородные граничные условия на полуоси и на отрезке для уравнения синус-Гордон // Алгебра и Анализ. 1991. Т. 3. С. 77-91 (совм. с Тарасовым В. О.)

[26] Конечнозонные аттракторы и переходные процессы типа ударных волн в интегрируемых системах // Зап. науч. семинаров ЛОМИ. 1992. Т. 199. С. 25-36

[27] Интегрируемые граничные задачи и нелинейные Фурье-гармоники // Зап. науч. семинаров ЛОМИ. 1992. Т. 199. С. 43-50

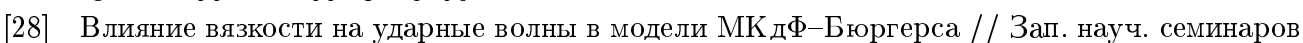
ЛОМИ. 1992. Т. 199. С. 37-42

[29] Периодическая задача для уравнения синус-Гордон, ее малые гамильтоновы возмушения и КАМ-деформации конечнозонных торов // Алгебра и Анализ. 1992. Т. 4. С. 42-78 (совм. с Куксиным С.Б.)

[30] Алгебро-геометрические решения нелинейной граничной задачи на отрезке для уравнения синус-Гордон // Матем. заметки. 1992. Т. 52. С. 19-28 (совм. с Итс А.Р.) 
[31] KdV equation with nontrivial boundary conditions at $x \rightarrow \pm \infty / /$ Singular Limits of Dispersive Waves. New York: Plenum, 1994. P. 175-183

[32] On the parametrization of finite-gap solutions by frequency vector and wave-number vector // Lett. Math. Phys. 1993. V. 28. P. 115-122 (with Kuksin S. B.)

[33] Конечнозонные решения двумерного изотропного ферромагнетика с фиксированными граничными условиями // ТМФ. 1993. Т. 95. С. 165-172

[34] Об ударных волнах в среде с кубической нелинейностью // ТМФ. 1993. Т. 97. С. 1-18

[35] О доме́нных стенках в изотропной модели Гейзенберга // ТМФ. 1993. Т. 95. С. 96-101

[36] Алгебро-геометрические неравенства, возникающие в теории возмущений: нелинейное уравнение Шрёдингера // Алгебра и Анализ. 1993. Т. 5. С. 67-82

[37] A perturbation of the continuous finite-gap spectrum by the discrete spectrum and asymptotics at $t \rightarrow \infty$ of the KdV equation solution with finite-gap behavior at $x \rightarrow \pm \infty / /$ Зап. науч. семинаров ЛОМИ. 1995. V. 212. Р. 43-50

[38] О локальных координатах на многообразии конечнозонных решений КдФ // Зап. науч. семинаров ЛОМИ. 1994. Т. 210. С. 47-56

[39] Об алгебро-геометрической параметризации торов постоянной средней кривизны // Ibid. 1994. T. 215. C. $50-64$

[40] Стабилизация модуляционной неустойчивости посредством деформаций Уизема: нелинейное уравнение Шрёдингера // Зап. науч. семинаров ЛОМИ. 1994. Т. 215. С. 65-76

[41] Уиземовские деформации, насыщающие модуляционную неустойчивость в нелинейном уравнении Шрёдингера // Письма в ЖЭТФ. 1994. Т. 59. С. 741-745 (совм. с Кудашевым В.Р.)

[42] Example jf shock waves in unstable media: the focusing nonlinear Schrödinger equation // Phys. Lett. A. 1994. V. 190. P. 255-258 (with Kudashev V. R.); Erratum // Ibid. V. 196

[43] Korteweg-de Vries equation with different finite-gap behavior at $x \rightarrow \pm \infty / /$ Russian Jour. of Math. Phys. 1995. № 2 